\title{
THERMAL ANALYSIS FOR INTERNAL COMBUSTION
}

\section{CYLINDER BLOCK}

\section{MUBARAK F. AL-DHAFIRI \& HASAN A. ALZENKI}

The Public Authority for Applied Education and Training

High Institute of Energy, Kuwait

\begin{abstract}
This paper presents a simulation and analysis for the thermal stresses of the internal combustion engine and analyzed its effects on cylinders and engine performance. The main aim of this paper is to make a simulation and analysis of the thermal stresses affect internal combustion engine or thermal fatigue. A simulation using Solidworks is used here to analyze the thermal stresses of ICE problem. It is found that the thermal stresses of cast carbon are of smaller value than that of the alloy steel. Thermal displacements and strains of alloy steel blocks are smaller than that of cast carbon. Cooling contributes in reducing thermal stresses, strains and displacements on both different blocks.

KEYWORDS: Internal Combustion Engines, Thermal stresses, Solidworks, Simulation, Strain, Displacement.
\end{abstract}

Received: Apr 10, 2019; Accepted: Apr 30, 2019; Published: Jun 24, 2019; Paper Id.: IJMPERDAUG201932

\section{INTRODUCTION}

The thermal fatigue of internal combustion engines is the principle on which this research is based on the used engine in experimental tests was a Dacia engine. If the negative effects in the case of any damage to the gears that constitute internal combustion engines, in order to mitigate the destruction caused by cracking, some comprehensive, complex, theoretical and empirical research on thermal fatigue, using theoretical and experimental approaches should be conducted. The study was conducted in three phases: first studying the thermal component of the partial mechanisms, to study and conduct an experimental determination of the changing fields of the surface temperature of the components of the device, and to perform an experiments on heat life samples exposed to different forms of thermal stress.

This study aimed to is to solve the complex problems of internal combustion engines (ICE) by controlling a new, original, theoretical and empirical knowledge about the heat exhaustion occurring in machines, which allows the transfer of heat from the combustion chamber to the cooling fluids of motors installed on automobiles [1].

It is known that cracks resulted from thermal fatigue appear on the surface and inside the outer layers of heat transfer parts. The specific thermal fissures develop gradually due to periodic changes in temperature. These cracks, on the upper layers and on the surface of the machine parts (although operating conditions are most appropriate), limit their use in situations that have adverse effects on the energy and economic indicators of the engine [2], [3]. 


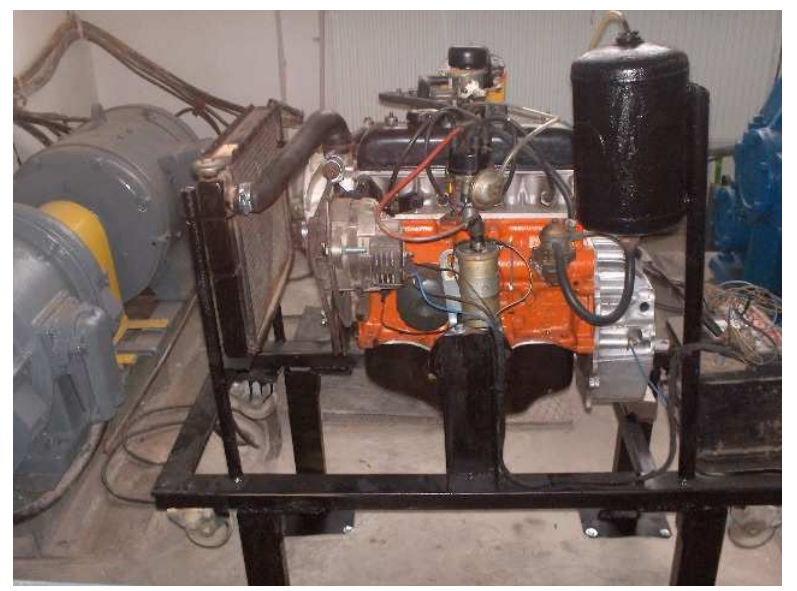

Figure 1: Experimental Bench to Measure the Temperature Values of ICE

There are many research discussed this issue; in this study, the researcher tried Amit V. Paratwar, D.B. Hulwan (2013) heat transfer and process flow analysis. The cover of the current average diesel engine cooling turbine refrigeration works of 6 cylinders, and examine the factors that affect cooling performance. To optimize the parameters listed CFD analysis of steady state verification and validated experimental results.

Martin G. and S. Olle (2015) tried to develop a model of diesel piston thermal analysis was used in the engines of Volvo Cars. Enhances thermal analysis model for identifying potential piston thermal loads full of drive and can be used as condition limits when CFD simulation of combustion. The study might be a help in the design of the piston.

Shobam. And Shekhar (2016) performed thermal analysis of engine block with fins. Parametric model was developed for the engine block fins in a 3D program Solidworks is made and thermal analysis on the fins and mass to determine the temperature change in the interim situation in stable condition with and without looking over time. The analysis is performed by using different materials. In this study two models were created in the program and the modified design was analyzed the form itself, and a comparison of the two models according to the geometry and the materials were analyzed. New materials were selected such as aluminum alloy 1050 for this analysis.

Vinay A. and Himanshu A.(2016)a three dimensional solid model of piston including piston pin is designed with the help of Solidworks software was constructed. The temperature, total heat flux are calculated to investigate factor of safety and life of the piston assembly using ANSYS workbench software. Aluminum alloy was used as piston material. The transient stress analysis results also help to improve component design at the early stage and also help in reducing time required to manufacture the piston component and its cost.

Vinay A. and Himanshu A.(2016) constructed a 3D solid model design of the piston, including the piston pin with the help of Solidworks software. The temperature is calculated, the total flow Heat and Safety factor and piston set age using ANSYS Workbench. Aluminum alloy is used as a piston. Stress test results also help transit to improve the design of the components in the early stage and also help to reduce the time required to manufacture the piston and component cost.

\section{MODELLING AND SIMULATION}

The modelling of the ICE is performed using the Solidworks software application. Figure 2 shows the cylinders of the ICE and engine block and its meshing. This engine consists of four cylinders. All specifications of the model and modelling parameters. 

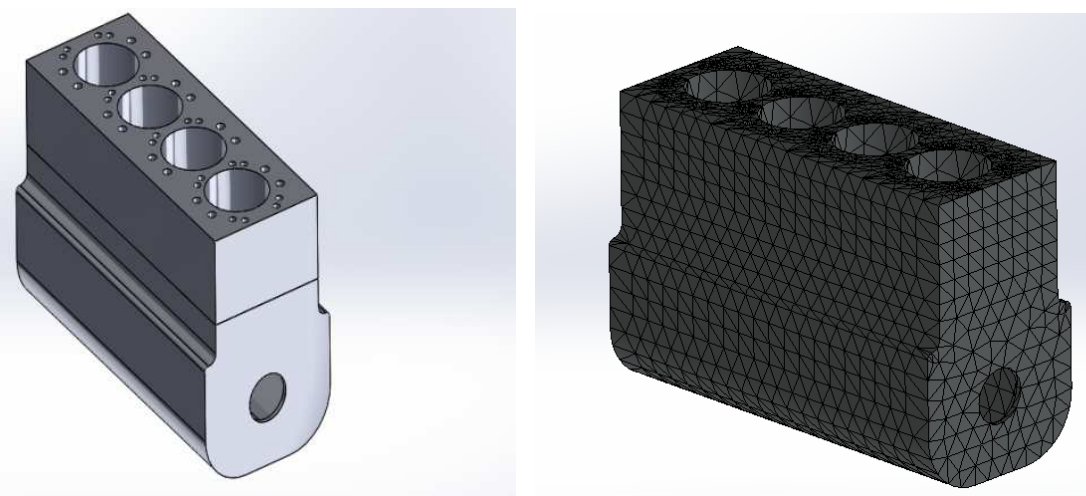

Figure 2: Cylinder Block of the ICE and its Meshing

This simulation will show engine thermal stress inside cylinders in every stroke, the simulation will be in two different ways, the first one is showing thermal stresses without engine cooling, and the second one will be with engine cooling, water convection data as in table 1 below.

Engine firing order starts from cylinder number 1,3,4,2 ( Red, Brown, Blue, Light Blue) so the thermal stress on each cylinder is shown on the Table 1 below, the cooling process for the engine is applied to show cooling efficiency.

Table 1: Thermal Loads

\begin{tabular}{|c|c|c|c|}
\hline Load Name & Load Image & \multicolumn{2}{|c|}{ Load Details } \\
\hline $\begin{array}{c}\text { Red } \\
\text { Cylinder }\end{array}$ & & $\begin{array}{l}\text { Entities: } \\
\text { Temperature: }\end{array}$ & $\begin{array}{c}\text { Power Stroke } \\
500 \mathrm{C}\end{array}$ \\
\hline $\begin{array}{c}\text { Blue } \\
\text { Cylinder }\end{array}$ & & $\begin{array}{l}\text { Entities: } \\
\text { Temperature: }\end{array}$ & $\begin{array}{c}\text { Intake Stroke } \\
\text { 37C }\end{array}$ \\
\hline $\begin{array}{c}\text { Brown } \\
\text { Cylinder }\end{array}$ & & $\begin{array}{l}\text { Entities: } \\
\text { Temperature: }\end{array}$ & $\begin{array}{c}\text { exhaust stroke } \\
200 \mathrm{C}\end{array}$ \\
\hline $\begin{array}{l}\text { Light Blue } \\
\text { Cylinder }\end{array}$ & & $\begin{array}{l}\text { Entities: } \\
\text { Temperature: }\end{array}$ & $\begin{array}{l}\text { compression stroke } \\
\text { 110C }\end{array}$ \\
\hline Engine Head & & $\begin{array}{l}\text { Entities: } \\
\text { Convection } \\
\text { Coefficient: }\end{array}$ & $\begin{array}{l}\text { Engine Head cooling } \\
\text { from water } \\
1000 \mathrm{~W} /\left(\mathrm{m}^{\wedge} 2 \cdot \mathrm{K}\right)\end{array}$ \\
\hline
\end{tabular}




\section{RESULTS AND DISCUSSIONS}

Figure 3 shows the temperature distribution with cooling of cast iron engine block. The red areas have more temperatures than that of blue areas.

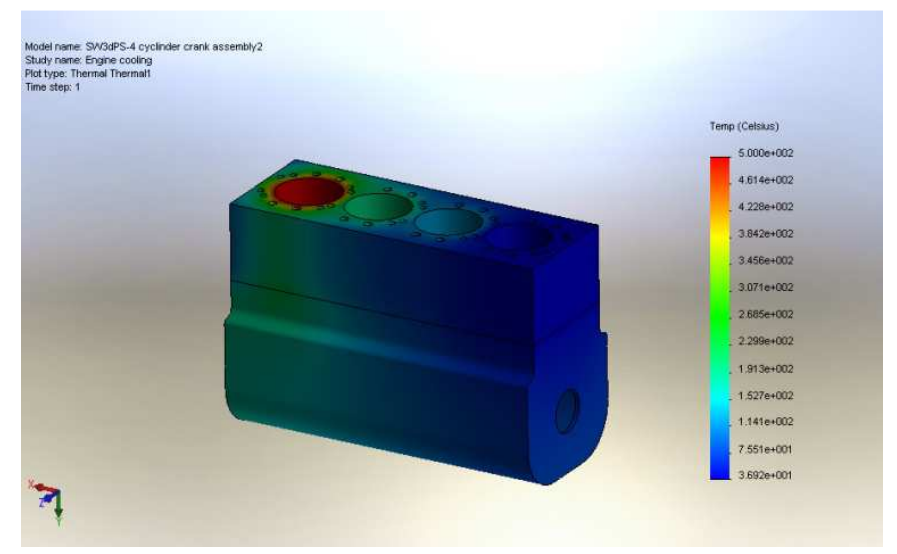

Figure 3: Temperature Distribution of Cast Carbon ICE Block

Figure 4 shows the Cast carbon ICE block thermal stress-Von-Mises stresses.

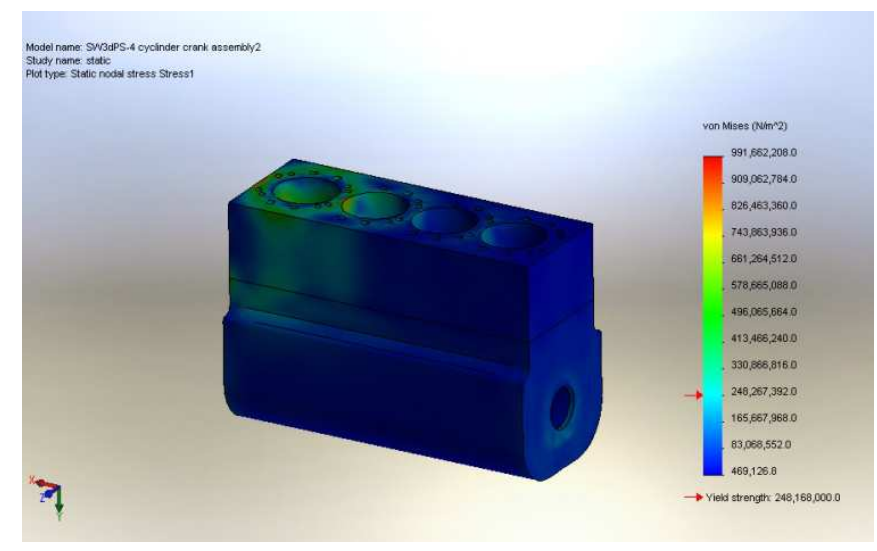

Figure 4: Cast Carbon ICE Thermal Stresses Distributions

Figure 5 shows the displacement of the cast Carbon ICE Block. The red areas have more displacements and thermal strains. Also figure 6 shows the thermal strains of the same block.

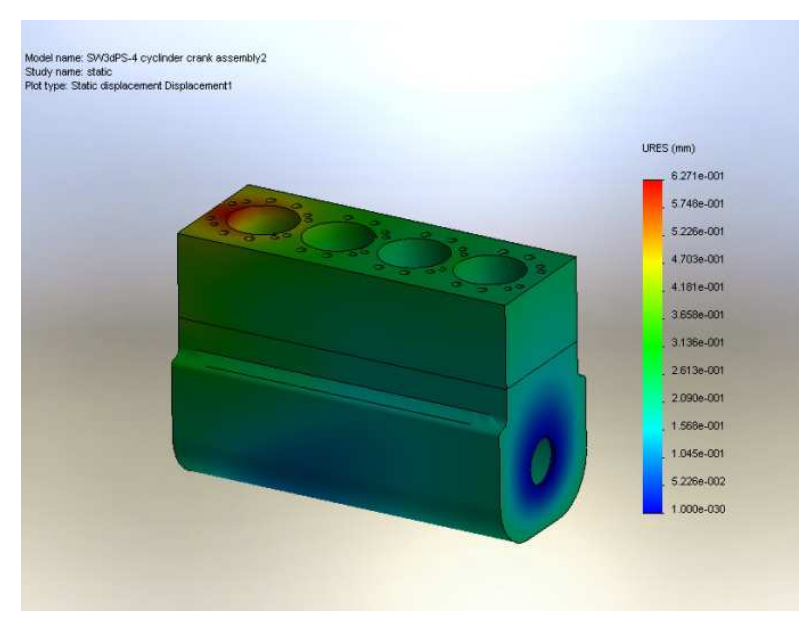

Figure 5: Displacements of Cast Carbon Engine Block 
Figure 6 shows the thermal strains distribution of the cast carbon ICE block.

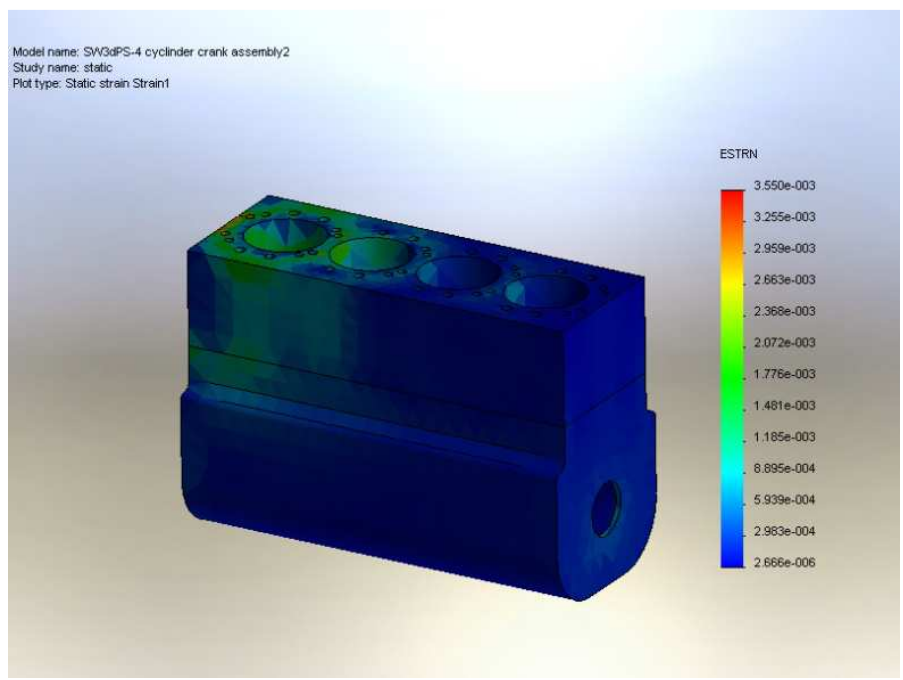

Figure 6: Thermal Strains Distribution of the Cast Carbon ICE Block

Figure 7 shows the cast carbon ICE cylinder block temperature distribution without cooling.

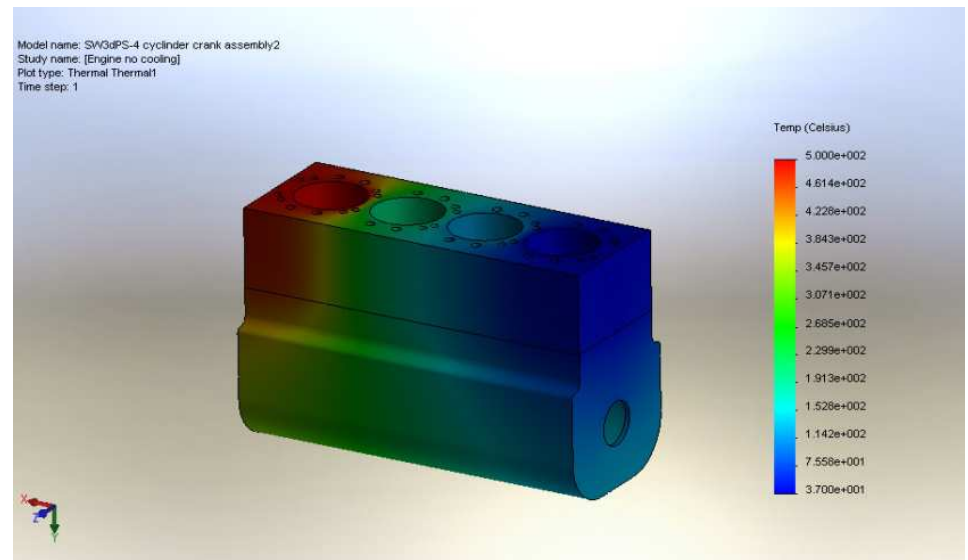

Figure 7: The Cast Carbon ICE Cylinder Block Temp. Distribution without Cooling

Figures 8 to 10 show the Cast carbon block: thermal stress, strain and displacement.

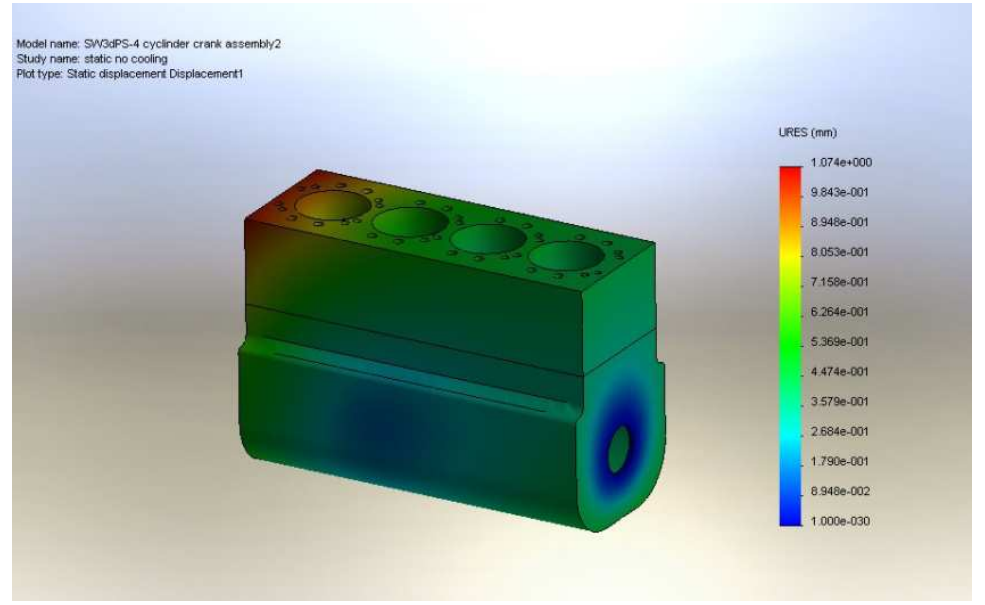

Figure 8: The Displacement of the Cast Carbon Block without Cooling 


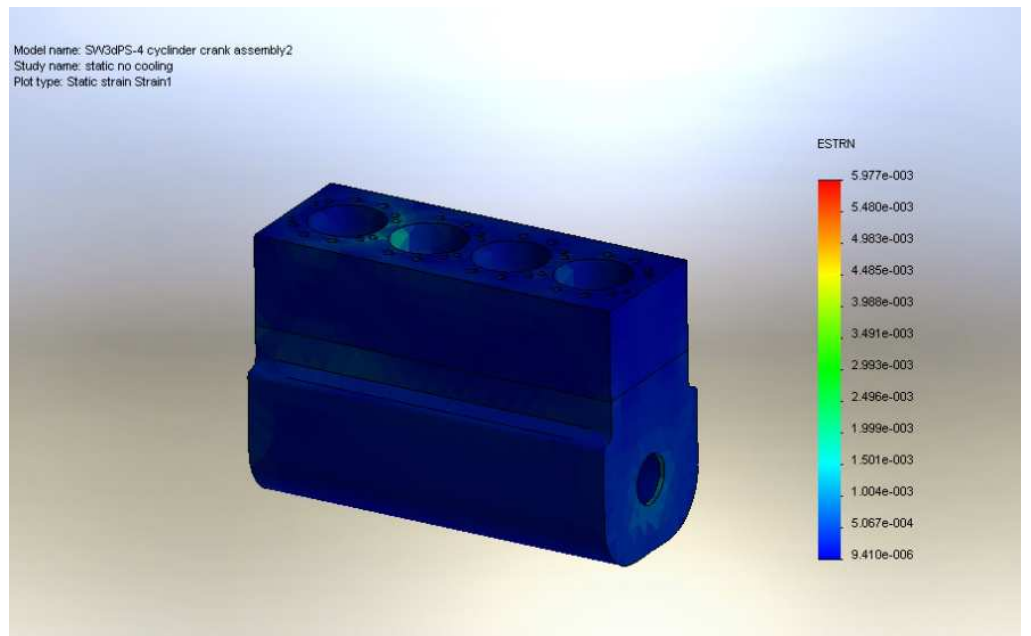

Figure 9: The Strain Distribution of the Cast Carbon Block without Cooling

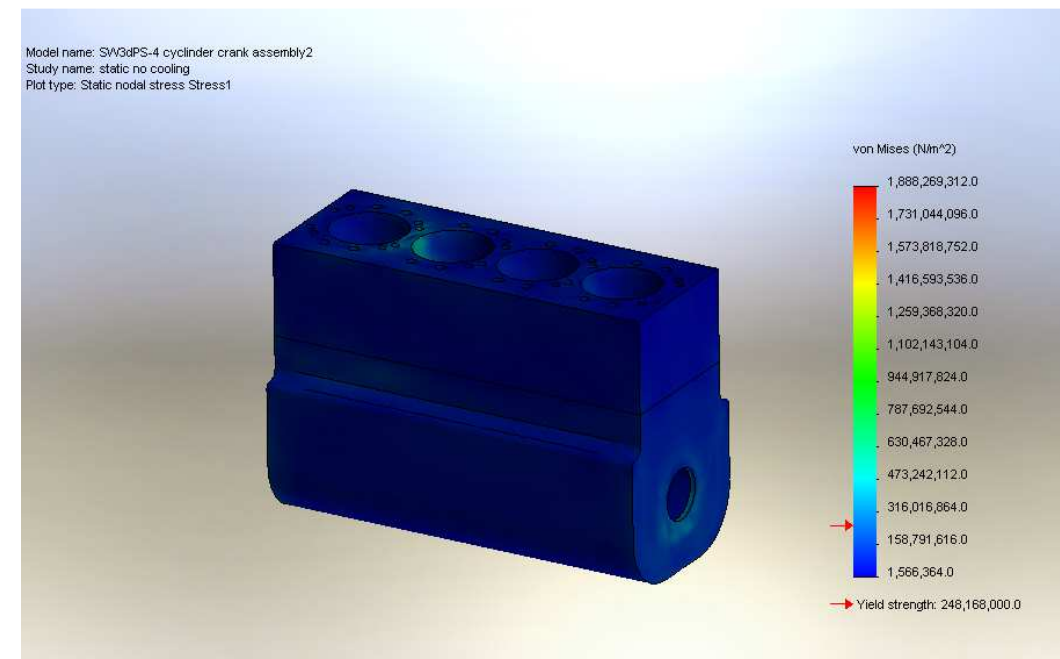

Figure 10: The Thermal Stresses Distribution of the Cast Carbon Block without Cooling

Figure 11 shows the alloy steel ICE block temperature distribution with cooling.

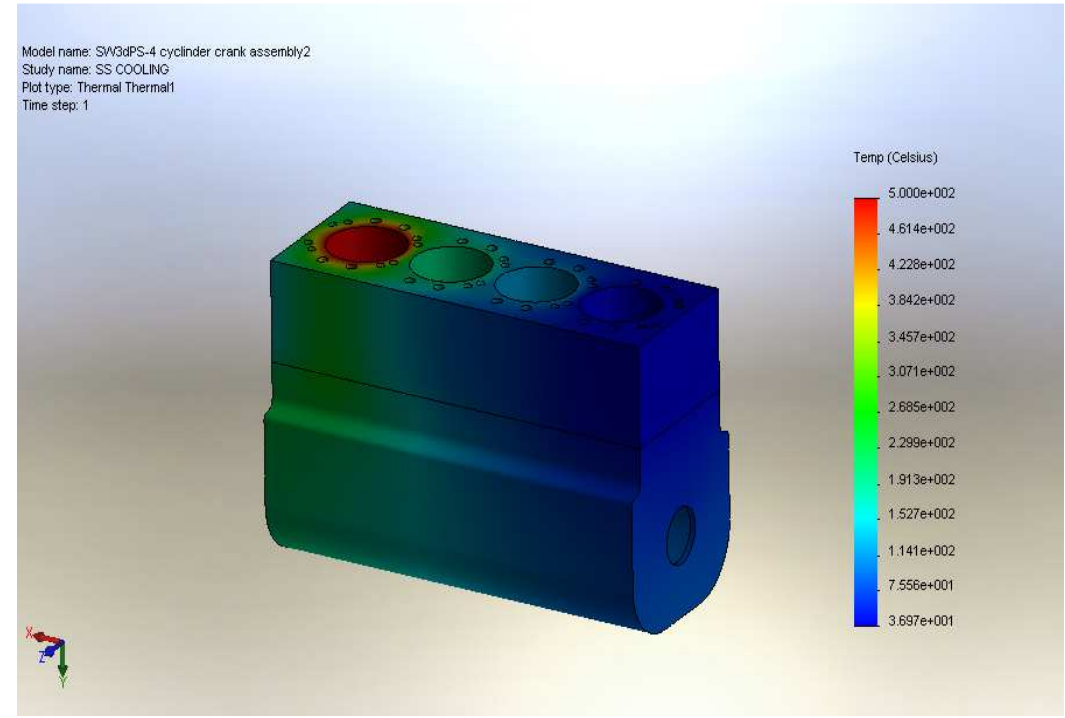

Figure 11: Alloy Steel ICE Block Temperature Distribution with Cooling 
Figure 12 to 14 show the alloy steel thermal stress, strain and displacement of the ICE with cooling.

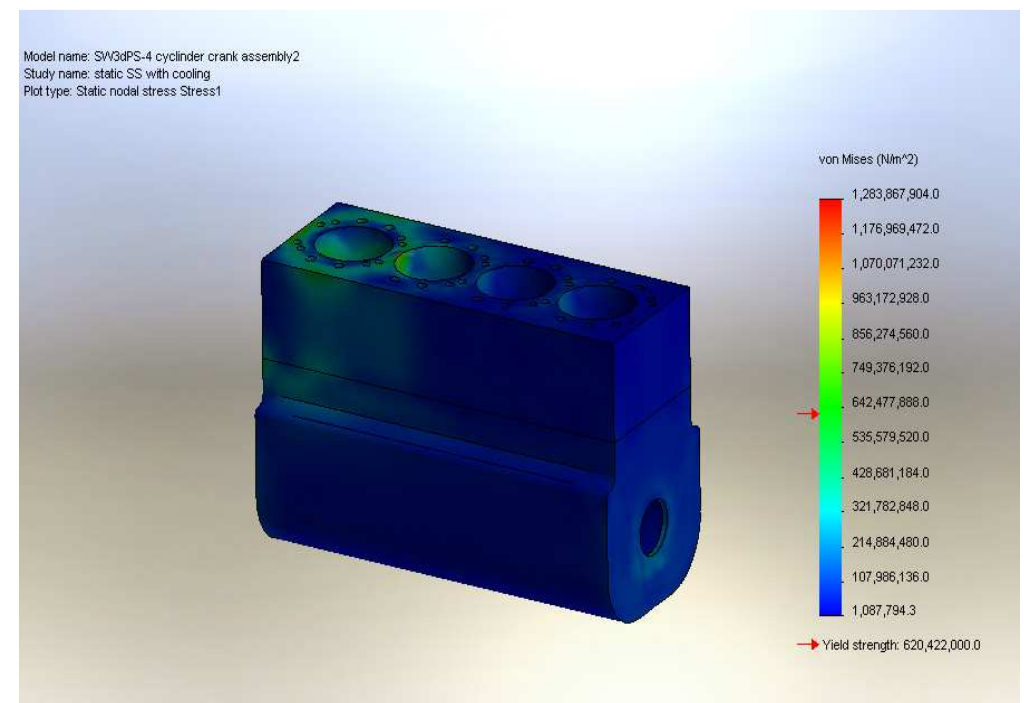

Figure 12: Alloy Steel Thermal Stress of the ICE with Cooling

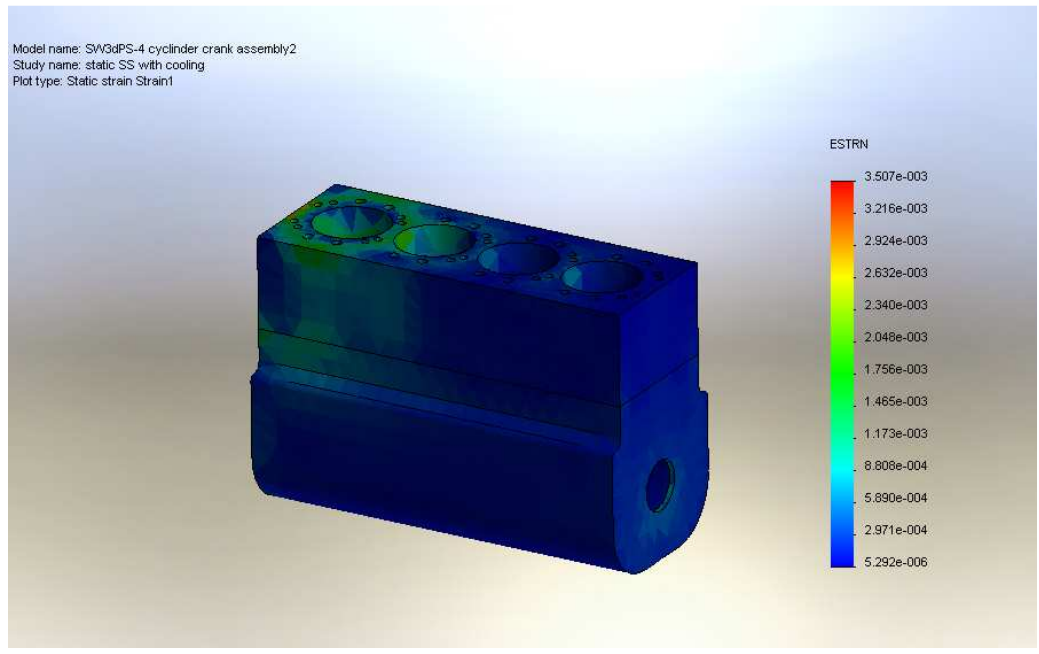

Figure 13: Alloy Steel Thermal Strain of the ICE with Cooling

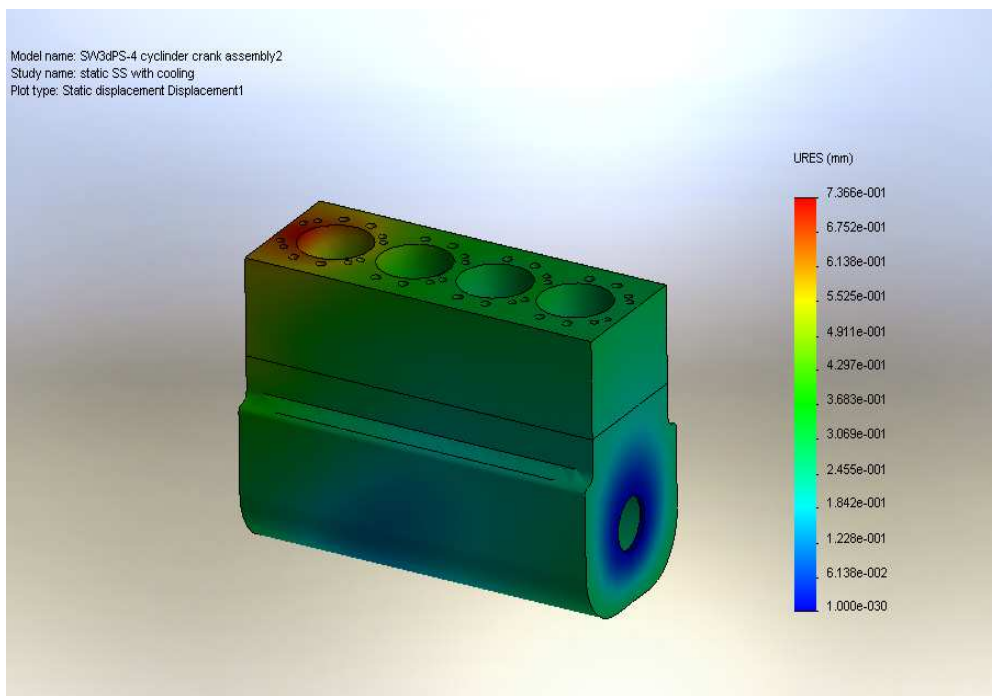

Figure 14: Alloy Steel Thermal Displacement of the ICE with Cooling 
Figure 15 shows the alloy steel ICE block temperature distribution without cooling.

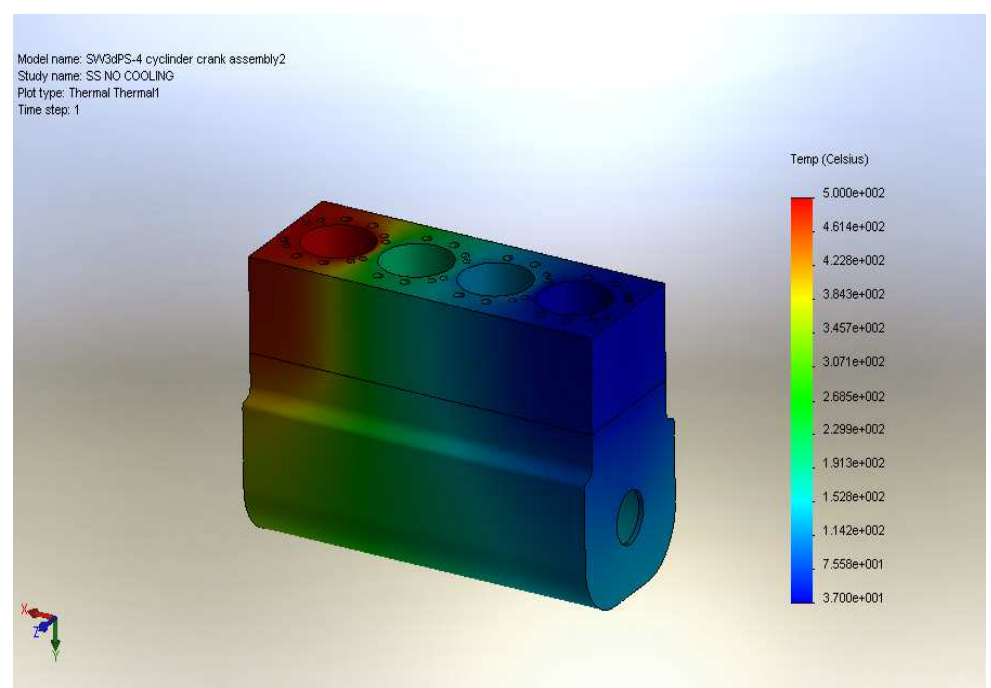

Figure15: Alloy Steel ICE Block Temperature Distribution without Cooling

Figure 16 to 17 show the alloy steel thermal stress, strain and displacement of the ICE block without cooling.

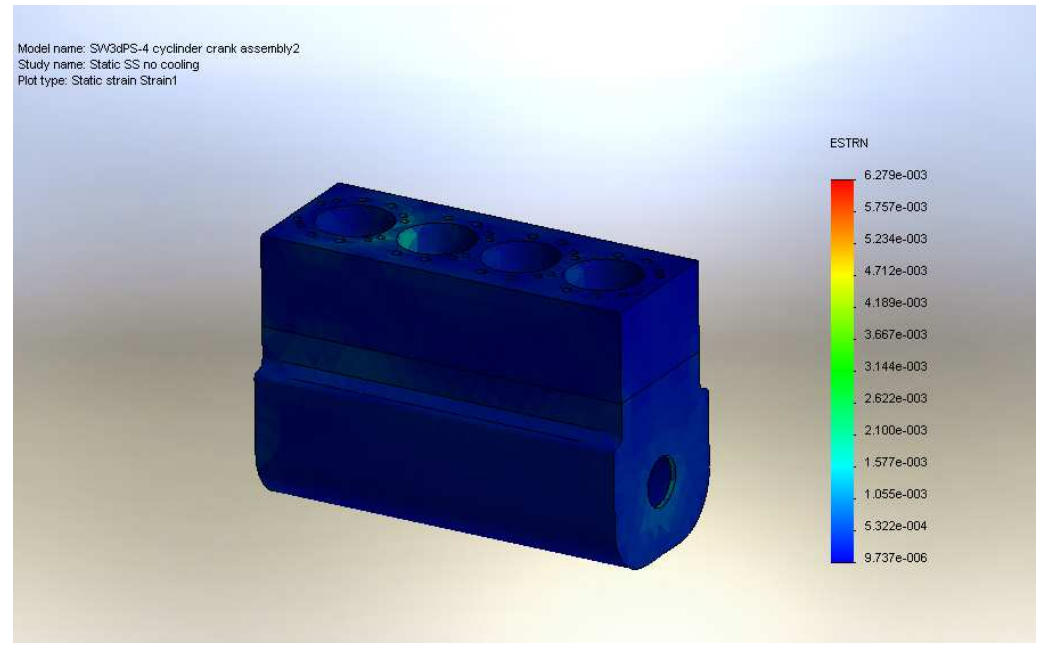

Figure 16: Alloy Steel Thermal Strain of the ICE Block without Cooling

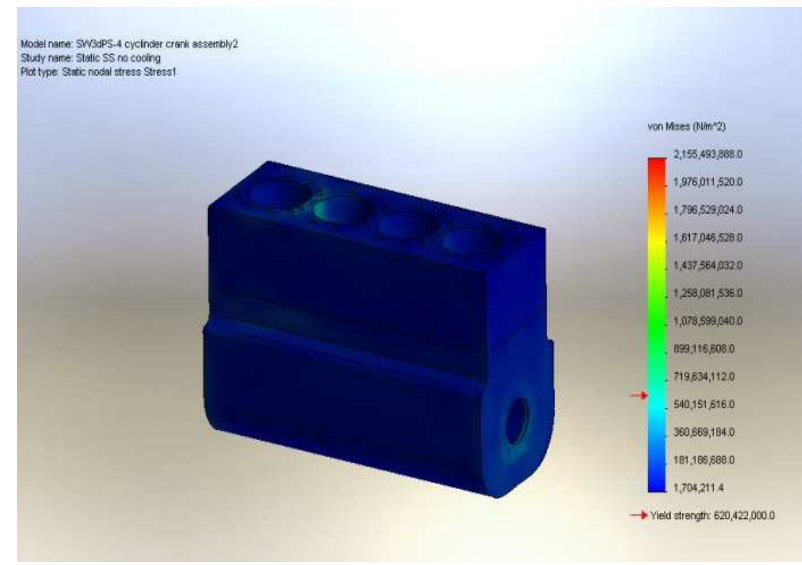

(a)

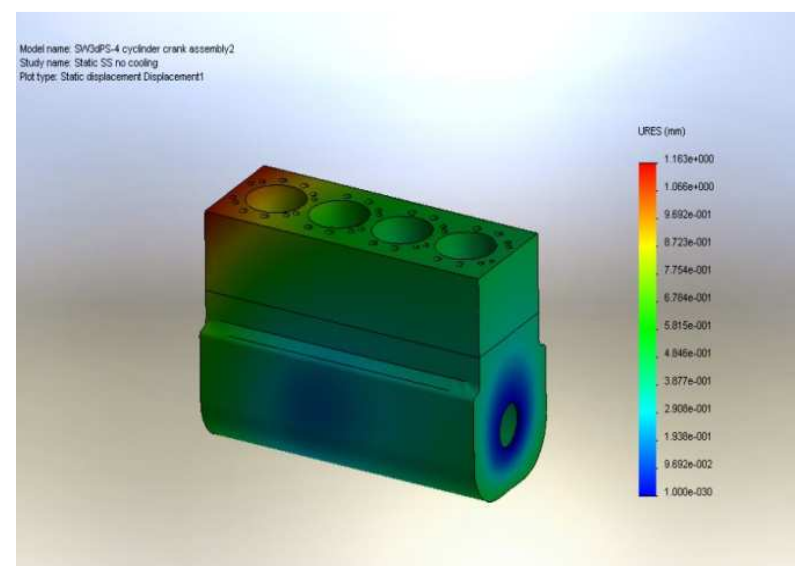

(b)

Figure 17: Alloy Steel Thermal Stress and Displacement of the ICE Block without Cooling 


\section{CONCLUSIONS}

Studying the thermal stresses and temperature distributions and also the thermal strains and displacement of the ICE block with different materials is very important issue especially using qualified finite and simulation and modelling software like Solidworks gives the opportunity to determine which of the materials studied is the best. It is found that the thermal stresses of cast carbon are of smaller value than that of the alloy steel. Thermal displacements and strains of alloy steel blocks are smaller than that of cast carbon. Cooling contributes in reducing thermal stresses, strains and displacements on both different blocks.

\section{REFERENCES}

1. Moran and Shapiro(1995) Fundamentals of Engineering Thermodynamics Third Edition.

2. Stone (1992). Introduction to Internal Combustion Engines Second Edition.

3. Pulkrabek (1997). Engineering Fundamentals of the Internal Combustion Engine First Edition.

4. John B. Howard (1988). Internal Combustion Engine Fundamentals First Edition.

5. Annals Of Faculty Engineering Hunedoara - International Journal Of Engineering copyright University Politehnica Timisoara, Faculty of Engineering Hunedoara, 5, Revolutiei, 331128, Hunedoara,-ROMANIA

6. Fernando Salazar (1999). Internal Combustion Engines Department of Aerospace and Mechanical Engineering University of Notre Dame Notre Dame, IN 46556, Printed on April 30, 1999.

7. Uzuneanu K., Panait T., Drăgan M. - Thermal Stresses in the Combustion Chamber of a Spark Ignition Engine Fueled with Ethanol-Gasoline Blends. Bulletin of the Transilvania University of Brasov Vol. 2(51)Series I, ISSN 2065-2119, Special Issue No.I, Vol 2, 2009 ISBN 978-973- 598-521-9, pg. 599-606 (CNCSIS B).

8. Ahmed A Al-Beiruti, Dr.Basim M Al-Quraishi \& Isam Ezzulddinyousif, "Thermal Effects on Diesel Engine Piston and Piston Compression Rings", Eng. \& Tech. Journal, Vol. 27, No.8, 2009.

9. K. Singh, 2004, Automobile engineering vol. II, Standard Publishers Distributors, Delhi.

10. Murali, K. M., Seshagiri, R. V., Murthy, P. V. K., \& Reddy, T. K. K. (2012). Performance evaluation of a low heat rejection diesel engine with carbureted ethanol and jatropha oil.

11. Uzuneanu, K., Scarpete, D., Panait, T. - Study on Thermal Stress Occurring in the Burning Chamber of an Ethanol-Gasoline Fueled Spark Ignition Engine - Conference "MOTAUTO' 01", 17-19 October 2001, Varna, Bulgaria; Proceedings ISBN 95490272-6-0, Vol.I, pag.99-103.

12. A. V. Paratwar, D.B Hulwan. Surface Temperature Prediction and Thermal Analysis of Cylinder Head in Diesel Engine International Journal of Engineering Research and Applications (IJERA) Vol. 3, Issue 4, Jul-Aug 2013, pp.892-902 892

13. M. G.Sandin (2015).Thermal Analysis of a Diesel Piston and Cylinder Liner using the Inverse Heat Conduction Method Master's thesis in Applied Mechanics Department of Applied Mechanics Chalmers University of Technology G"oteborg, Sweden 2015

14. Osiński, P., \& Cependa, P. Development of a method for determining micro-leaks and volumetric efficiency in pneumatic cylinders. 
15. S. Shrivastava, S. Upadhyay (2016). Thermal Analysis of IC Engine Cylinder Block with Fins Perpendicular to the Axis of Piston. International Journal of Mechanical and Industrial Technology ISSN 2348-7593 (Online) Vol. 3, Issue 2, pp: (139149).

16. Attar* et al., ( 2016). Transient Thermal Analysis Of Internal Combustion Engine Piston In Ansys Workbench By Finite Element Method. International Journal of Engineering Sciences \& Research Technology 5(6).

17. R. Mamat, N. Kamsah (2011) Thermal Analysis of SI-Engine using Simplified Finite Element Model. Proceedings of the World Congress on Engineering 2011 Vol III WCE 2011, July 6 - 8, 2011, London, U.K. 